\title{
Prakties-teologiese riglyne vir die drie kategorieë van visuele prediking
}

Author:
Barend J. van Tonder ${ }^{1}$
Affiliation:
1Department Practical
Theology, University of
Pretoria, South Africa
Correspondence to:
Ben van Tonder
Email:
benirma@mweb.co.za
Postal address:
PO Box 20750, Proteapark
0305, South Africa
Dates:
Received: 12 Apr. 2010
Accepted: 14 Sept. 2011
Published: 09 Dec. 2011
How to cite this article:
Van Tonder, B.J., 2011,
'Prakties-teologiese riglyne
vir die drie kategorieë van
visuele prediking', Verbum
et Ecclesia 32(1), Art. \#388,
11 pages. http://dx.doi.
org/10.4102.ve32i1.388

(C) 2011. The Authors. Licensee: AOSIS OpenJournals. This work is licensed under the Creative Commons Attribution License.
Met die verskyning van die TV-medium binne dieSuid-Afrikaanse milieu in die laat sestigerjare en vroeë sewentigerjare (vgl. Barnard 2009:192), het 'n nuwe wyse van kommunikasie die lig gesien. Grotendeels het dit meegebring dat die kommunikasiemedium van die woord deur die kommunikasiemedium van die beeld vervang is (vgl. Sweet 1999:200).Visuele kommunikasie het die mees ingrypende verskuiwing geword wat oor die afgelope vyf dekades plaasgevind het. Uiteraard het dit ' $n$ nuwe generasie na vore gebring, wat as die visuele generasie bekend staan, en binne die visuele taalkode kommunikeer.

Visuele uitbeelding word in hierdie artikel gestel as 'n legitieme vorm van homiletiese aanbieding naas die oratoriese aanbieding van die prediking. In hierdie artikel word drie kategoriee van visuele prediking word geidentifiseer, naamlik, (1) die visuele beeldpreek, (2) die visuele uitbeeldingspreek en die (3) visuele verbeeldingspreek. Praktiese riglyne vir elke vorm van visuele prediking word in hierdie artikel ontwikkel, sodat die visuele geletterdheid van die prediker kan verhoog.

\section{Inleiding}

Met die verskyning van die TV-medium binne die Suid-Afrikaanse milieu in die laat sestigerjare en vroeë sewentigerjare (vgl. Barnard 2009:192), het 'n nuwe wyse van kommunikasie die lig gesien. Grotendeels het dit meegebring dat die kommunikasiemedium van die woord deur die kommunikasiemedium van die beeld vervang is (vgl. Sweet 1999:200). Tot in daardie stadium was die telegraaf en radio die mees effektiewe kommunikasiemediums van die uitsaaikultuur (Niemandt 2007:107). Televisie se koms het egter die ander kommunikasievorme dramaties omver gegooi, deur met die oogsintuig te doen wat die telegraaf en radio tot op daardie stadium met slegs die gehoorsintuig kon regkry (Barnard 2009:192). So het TV die medium geword wat die uitsaaikultuur in 'n hoër rat oorgeskakel het (Barnard 2009:193).

Van die eerste oomblik van TV-kommunikasie, het hierdie tegnologiese deurbraak die wyse waarop mense kommunikeer radikaal verander (Barnard 2009:192; vgl. Garrety 2005:90). Deur duidelike en eenvoudige beelde te skep, het die TV-medium onmiddellik miljoene geskrewe en gesproke woorde vervang (Miller 1994:59). Sodoende het 'n nuwe 'alfabet' tot stand gekom wat 'n opwindende wêreld van beeldende denke geopen het (Jensen 2005:7).

Terselfdertyd het die TV aanleiding gegee tot 'n nuwe verstaan van die werklikheid (Johnston 2001:48). 'n Verskuiwing in wêreldbeeld wat die sekerhede en liniêre denke van die modernisme onder verdenking geplaas het, is deur hierdie kommunikasiemedium aangehelp (Barnard 2009:1940). Jensen merk op dat die visuele element van die huidige kultuur parallel loop met die opkoms van post-modernisme (Jensen 2005:9).

\section{Die taal van die visuele generasie}

Massa-kommunikasie deur middel van beeld het wêreldwyd die mees ingrypende verskuiwing geword wat oor die afgelope vyf dekades plaasgevind het (vgl. Barnard 2009:174; Garrety 2005:90). Uiteraard het dit 'n nuwe generasie na vore gebring, wat van kleins af aan hierdie styl van kommunikasie blootgestel is, en dus ook binne die konteks van die kerk nie deur tradisionele literêre prediking en bediening aangespreek is nie (Zander 2006).

Die geweldige invloed van die TV-medium op veral die jonger geslagte het tot 'n nuwe generasie van 'kykers' eerder as hoorders aanleiding gegee, wat kommunikasie-impulse anders verwerk (vgl. Garrety 2005:90; Sweet 1999:131). Met die woorde van Smith (2006) word dit soos volg gestel: 'TV shaped the way we receive messages'. In aansluiting hierby onderstreep McLuhan (1994:xxi): 'We shape our tools and afterwards our tools shape us'. 
Hierdie geslag wat deur die TV-medium gevorm is, staan vandag as die Generasie X'ers bekend (Brink 1997:3; Carstens 1997:2). Generasie X was die eerste van die drie geslagte wat primêr deur beeld kommunikeer en daardeur aangespreek word (vgl. Johnston 2001:49). 'n Tweede generasie wat deel vorm van die visueel-gedrewe geslag, bekend as Generasie $Y$, het twee dekades later op hierdie eerste geslag gevolg (Hestorff 2005:1). 'n Ingrypende verskuiwing binne die wêreld van die elektroniese media en kommunikasie het hierdie tweede generasie tot stand gebring, naamlik die verskyning van die Internet (Kimball 2003:2). Waar die Generasie X'ers as die TV-geslag bekend gestaan het (vgl. Johnston 2001:49), het die Generasie Y'ers as die Internetgeslag bekend geword (Sweet 2006:1).

'n Derde geslag, bekend as Generasie Z (McCrindle 2009:1), het twee dekades ná die Y-generasie, by hierdie eerste twee geslagte aangesluit as deel van wat vandag oorkoepelend as die visuele generasie bekend staan (McDougall 2009:3). Al drie geslagte het sterk onder die invloed van die elektroniese skerm opgegroei en bepaalde kommunikatiewe en selfs neurologiese aanpassings deurgemaak wat uiteindelik 'n sosiologiese omwenteling tot gevolg sou hê (Blackwood 2009a:1; vgl. Toplak 2004:1;).

Sentraal binne die kommunikasie aan die visuele generasie, staan die beeld-kommunikasie of visuele kommunikasie as 'n selfstandige en gelykwaardige taalkode naas die literêre en verbale medium van die woord (Sweet 1999:211). Hieroor oordeel Sweet (2006):

If you do not understand that film has been the major culturaldynamic of the 20th century, and you are not constantly learning and getting film and media savvy, you cannot communicate to this generation.

(Sweet 2006:2)

Sweet (2006) bevestig dat die visuele generasie se twee gunsteling tydverdrywe juis binne die visuele kommunikasiebestek van die Internet en film val (Sweet 2006:2). Hy bekragtig dit in 'n onderhoud met Rick Lawrence: 'These kids are saying to us: "You want to communicate to us? You want to speak our language? You gotta know about film and Net"' (Sweet 2006:2).

Hierdie visuele kommunikasie het daarom nie bloot tegnologiese ontwikkeling of vermaaklikheidstimuli tot gevolg gehad nie, maar het 'n radikaal nuwe táál tot stand gebring (Sweet 2006:2; Garrety 2005:90). 'n Taal só vreemd en selfs bedreigend (vgl. Lischer 2005:12), maar met soveel moontlikhede, impak en impetus (Romanowski 2007:18), dat dit die totale kommunikasiegestalte vir altyd verander het (vgl. Barnard 2009:173; Sweet 1999:36). Soos Johnston (2001:49) dit stel: '... as a result it's created a whole new grammar'. Meer as ooit tevore het die bekende uitdrukking, 'a picture says more than a thousand words', nuwe betekenis verkry. Korporatiewe prediking en liturgie binne hierdie hedendaagse visuele konteks, en kommunikasie aan hierdie beeld-gedrewe generasies, sal dus volgens Atkinson (2006:1) in die taal van multi-sensoriese verkondiging en aanbidding moet geskied. Hiermee word bedoel dat die totale aanbiddingservaring - wat natuurlik die prediking insluit - die mens se sintuie sal moet aanspreek deur die volledige menslike liggaam heelbreingeoriënteerd by die aanbidding te betrek; aanbidding wat die hart, siel, krag én verstand inkorporeer (vgl. Blackwood 2009b:1 ; Rognlien 2005:voorwoord; Vos \& Pieterse 1997:115).

Willingham (2007) bevestig dat die kerk vandag binne 'n oudiovisuele konteks staan:

Every day, we are surrounded by a multisensory collage of video, graphics, colour, movement, displays and media that tap into all five of our senses - sight, smell, hearing, touch and taste. All are intended to get our attention and convey compelling information in a short timeframe.

(Willingham 2007:1; vgl. Detweiler 2005b:91; Pagitt 2005:87)

Blackwood (2009a:1) gebruik dieselfde oorkoepelende term, genaamd 'multi-sensoriese prediking,' wanneer hy hierdie nuwe styl van prediking beskryf (vgl. Sweet 1999:210). Volgens Henry is multi-sensoriese kommunikasie 'n gelyktydige visuele (wat ons sien), ouditiewe (wat ons hoor) en kinestetiese (wat ons voel) kommunikasie (Henry 2000:1; Vos \& Pieterse 1997:116-117). Sweet (2006:4) noem dit op sy beurt 'EPIC': 'Experiential,' 'Participatory,' 'Image-based' and 'Communal'.

'Image-based' kommunikasie en belewing waarvoor binne die erediens en veral die prediking gepleit word, kan ook as beeldgedrewe prediking bekend staan. Wanneer daar egter van beeldgebaseerde kommunikasie gepraat word, het dit weinig alleen met geprojekteerde skyfies, foto's of video-insetsels te make (vgl. Burke 2005:76; Denison 2006:25). Dit gaan eerder om die totale verpakking van die kommunikasie in 'n nuwe taal; met ander woorde inhoud, teks en aanbieding binne 'n omvattende visuele verpakking, kunstig gevul met rituele, simbole, gelykenisse, metafore, beeldryke kommunikasie, stories, getuienisse, visuele illustrasies, grafiese kuns, beeldende kuns, uitvoerende kuns, verbeelding en sensoriese belewing (Denison 2006:26; Sweet 2006:4). 'A poetic ministry would not be afraid of any and all possible combinations of words, images, objects, gestures, sounds, smells and tastes' (Sweet 1999:173).

\section{'n Prakties-teologiese begronding van die visuele taal}

Meeste predikers het met ongemak bewus geraak van die uitdaging om steeds in die oratoriese taalkode te kommunikeer terwyl veral die visuele generasie min aanklank by daardie soort prediking gevind het (Hogan 2008:146-147; vgl. Lischer 2005:12; Zander 2006). In besonder was dit die onvermoë van talle predikers sowel as die meer gevestigde gemeentelede om hierdie verskuiwing binne hulle eie denke te maak, wat vervreemding tot gevolg gehad het en uiteindelik die kerklike konteks irrelevant vir die jonger geslagte gemaak het (vgl. Denison 2006:xi).

Volgens Zander het selfs dinamiese kerke met dinamiese predikers spoedig besef dathulle die volgendegeslag grootliks 
verloor (Zander 2006). Kontras in die kommunikatiewe aanslag en informasie-verwerking tussen die geslagte wat binne 'n letterkultuur opgegroei het en die nuwere geslagte wat binne 'n beeldsendkultuur groot geword het, was dramaties (Barnard 2009:193; vgl. Sweet 1999:175). Kerke wat nog binne die rasionele letterkultuur van kommunikasie vasgevang was, het begin worstel met oorlewing en kritiek (vgl. Barnard 2009:195). Aan die ander kant van die spektrum was daar die kontemporêre kerke wat weer kommunikatiewe aanpassings gemaak het ter wille van die verkondiging en bediening, hoewel hierdie aanpassings nie altyd teologies verantwoord of wetenskaplik na behore begrond was nie (Long 2001:10; vgl. Lischer 2005:24 \& 25; Zander 2006). 'n Ongelukkige gevolg hiervan was tweeledig van aard: aan die een kant is die waarde van die visuele kommunikasie vir te lank as negatief, minderwaardig en bedreigend beoordeel (Detweiler 2005:82; Lischer 2005:23; Long 2001:10; vgl. Sweet 1999:202). Aan die ander kant is die visuele medium klakkeloos deur kerke en predikers oorgeneem, sonder om kritiese interaksie daarmee te bewerkstellig nie (vgl. Pagitt 2006; Romanowski 2007:23).

Vandag word indringend gepleit vir 'n meer gebalanseerde benadering tot die visuele medium (De Gruchy 2009:196-198; Hogan 2008:147; Romanowski 2007:15). Só 'n wetenskaplikverantwoordbare vertrekpunt vereis 'n duidelike praktiesteologiese begronding van die visuele kommunikasie binne die kerklike praktyk van die homiletiek (vgl. Hogan 2008:147). Om daarby uit te kom sal die visuele medium binne 'n teologiese raamwerk geplaas moet word, waar verantwoordbaar oor die prakties-teologiese waardering en uiteindelike aanwending daarvan besin kan word (vgl. De Gruchy 2009:198). Binne die navorsingsterrein van die homiletiek is daar tot op hede nog nie genoegsaam oor hierdie radikale verskuiwing binne die dimensie van kommunikasie nagedink nie (Denison 2006:xi; Hogan 2008:146-147). Meeste hedendaagse navorsers soos onder andere Dingemans (1996:123), wat oor die post-moderne hoorder nadink, sowel as Lischer (2005:23) en Immink (2009:123), konsentreer nog grootliks op die woordgebaseerde prediking of verbale kommunikasie, terwyl visuele kommunikasie as sekondêr afgemaak word (Detweiler 2005b:82; Lischer 2005:26).

Vanuit die nuwe hermeneutiek van die post-modernisme, word taal vandag wyer as spraak verstaan en sluit dit ook beeld, gebare en stilte in (Woodbridge 2007:2). Om hierdie rede pleit McDougall (2009:3) vir 'n 'visual literacy', oftewel 'n visuele geletterdheid, wat vandag net so noodsaaklik is vir effektiewe kommunikasie soos woordgeletterdheid eeue gelede was (Sweet 1999:117). Hogan (2008) verklaar dat:

Many of the sermons that will be prepared in the future will not just be made up of the spoken word. That spoken word will be accompanied by visual images of other words, pictures or film clips. The electronic capabilities that are now available to preachers - computers, PowerPoint, sound and film clips will have great potential for radically altering the sermon event. Listeners will expect more than the simple spoken word, a format that has changed little since the earliest centuries of church's history. It is imperative that all preachers become familiar and comfortable with these new possibilities.

(Hogan 2008:147)
Gebruik van visuele uitbeelding binne prediking word in hierdie artikel gestel as 'n legitieme vorm van homiletiese aanbieding (Jensen 2005:ix). Woorde faal predikers dikwels, en beelde kan juis hierdie leemte van woorde aanvul (Burke 2005:75; Campbell 1981:20; vgl. Hogan 2008:147). Visuele prediking is nie die nuutste modegier vir predikers wat op vermaaklikheid ingestel is nie (Blackwood 2009b:1; vgl. Lischer 2005:24-26), maar die erkenning van die noodsaaklikheid van die mensgesentreerde heelbreinkommunikasie (vgl. Jensen 2005:ix). Visuele intelligensie sal indringend op 'n prakties-teologiese wyse ontwikkel moet word om hierdie geweldige kommunikasiegaping te oorbrug (vgl. Hogan 2008:147). Hiermee wil die betrokke artikel van hulp wees deur uiteindelik praktiese riglyne te ontwikkel wat binne 'n verantwoordbaar-kritiese prakties-teologiese raamwerk ingebed word en die visuele intelligensie van die prediker binne die prediking kan verhoog (vgl. Blackwood 2009a:2).

\section{Definiëring van visuele uitbeelding binne die visuele prediking}

Visuele uitbeelding binne die prediking kan kortliks as 'beeld' vir die doeleindes van hierdie artikel beskryf word. Beeld word verstaan as die sigtelike metafoor wat langs die orale metafoor of skriftelike metafoor as 'n selfstandige uitdrukkingsvorm van die visuele kommunikasie staan. Vyf betekenis-kategorieë van beeld kan volgens Jensen (2005:10) onderskei word:

1. Grafiese beelde - prentjies, standbeelde, kunstige ontwerpe, foto's.

2. Optiese beelde - spieëlbeelde, lig-projekterings.

3. Persepsuele beelde - sensoriese data, rekwisiete, illustratiewe hulpmiddels.

4. Denkbeeldige beelde - drome, herinneringe, idees, verbeelding.

5. Verbale beelde - metafore, analogieë, narratiewe en gelykenisse.

In hierdie artikel lê die fokus grotendeels op die eerste kategorie van beeld: grafiese of sigtelike visuele uitbeeldings. Hiermee word die projektering van optiese beelde ook ingeskakel soos dit tot die visuele vertoning daarvan op projeksie-skerms of plat oppervlaktes binne die erediensruimte betrekking het (Hogan 2008:147; vgl. Jensen 2005:10).

Visuele prediking en uitbeelding gaan egter nie alleen maar net oor die visuele projeksie van beelde op skerms of die konkrete uitbeelding daarvan op tekendoeke nie (Denison 2006:25). Hierdie wanpersepsie is steeds tiperend van die liniêre modernistiese denkpatroon wat volhou dat beelde bloot die punte wat gemaak word moet ondersteun (vgl. Campbell 1981:19-21; Hogan 2008:146; Johnston 2001:143). Só ' $n$ linkerbrein-fokus is nie wat met visuele uitbeelding in gedagte is nie, maar eerder ' $n$ verbreding na heelbreinkommunikasie waar die regterbrein ook volledig in spel kom (Blackwood 2009b:1; Johnston 2001:143). Om die regterbrein-kommunikasie te stimuleer sal visuele beelde 
dus 'n selfstandige rol moet vervul (Jensen 2005:140). Wanneer dan van visuele uitbeelding gepraat word, het dit nie slegs met foto's of tekenkuns te doen nie, maar sluit dit visuele uitbeelding in soos dit in die uitvoerende kunste deur byvoorbeeld die sigtelike genre van drama, dans en mimiek uitgebeeld word. Ook inkorporeer dit fisieke en persepsueelsigtelike hulpmiddels en rekwisiete wat die prediker tydens 'n visuele illustrasie binne die preek gebruik (Beach 2004:236; vgl. Burke 2005:75).

'n Verdere dimensie van visuele uitbeelding wat ook hier betrekking het, is die denkbeeldige uitbeelding wat aansluit by die vierde kategorie van beeld soos dit deur die stimulerende effek van visuele metafore of visuele narratiewe op die menslike verbeelding na die menslike bewussyn kom (vgl. Miller 2006; Vos 2007:22 ).

\section{Drie kategorieë van visuele preke met praktiese riglyne vir elkeen}

'n Vraag waarmee die prediker telkens sy of haar voorbereiding vir elke preek moet begin, word deur Miller (2006) aan die orde gestel: 'Wat sal in hierdie preek verbeeld word?' Hierdie vraag veronderstel dat die plek wat visuele uitbeelding binne die verkondigingsdimensie van die preek inneem, nie bloot terloops of as nagedagte geskied nie, maar 'n doelbewuste kommunikatiewe beklemtoning het. Enige prediker wat heelbrein wil kommunikeer, sal telkens hierdie vraag probeer beantwoord (vgl. McDougal 2009:12). Wanneer die prediker die gewoonte aanleer om hierdie vraag met die drie vrae te inkorporeer wat Willow Creek gemeente se predikers voor die aanvang van enige preekvoorbereiding vra, naamlik 'Wat wil ek hê moet mense leer?', 'Wat wil ek hê moet mense voel?' en 'Wat wil ek hê moet by mense verander?' (Beach 2004:235) gaan die prediking werklik relevant word vir die multi-sensoriese heelbrein- en visueelgedrewe mens.

Vervolgens word drie kategorieë van die visuele sigtelike prediking voorgehou. Elkeen van die kategorieë konsentreer op een of meer van die verskyningsvorme van die visuele metafoor soos dit binne 'n bepaalde visuele preeksoort tuiskom (vgl. Jensen 2005:124).

\section{Visuele beeldpreke}

'n Visuele beeldpreek, met ander woorde die visuele uitbeelding deur middel van grafiese beeld, sentreer rondom enkele visuele beelde, en in sommige gevalle slegs een enkele beeld, wat as deel van die preek op die vertoonskerm geprojekteer of andersins op ' $n$ plat oppervlakte in die erediensruimte uitgebeeld word - dit kan ook 'skermpreke' genoem word (vgl. Jensen 2005:140).

Visuele beeldprediking vereis gewoonlik 'n meditatiewe konteks waar genoegsame ruimte vir oordenking en kontemplasie rondom die uitbeelding toegelaat word. 'n Geprojekteerde beeld kan elektronies vertoon word, of daar kan van een of ander uitbeeldende kunsvorm soos die tekenkuns gebruik gemaak word (vgl. Jensen 2005:ix, xi).
Grafiese beelde is uiters kragtige kommunikasie-instrumente (Denison 2006:25; Mathewson 2007:3). Prentjies, foto's, tekenkuns, videosnitte en konkrete visuele hulpmiddels skilder beelde wat die hoorder en/of kyker begelei na ontdekkings en belewenisse waarby blote woorde nie noodwendig kan kom nie (Campbell 1981:20; Denison 2006:10; vgl. Sweet 1999:203; Jensen 2005:133). Tegnologiese kommunikasiemediums soos PowerPoint maak dit vandag moontlik om letterlikénige kunswerk tot binne-in die erediens te bring (Niemandt 2007:115). Sodoende word die wêreld van die preek drasties vergroot, die inligting- en belewingskopus van die preek verbreed, en die hoorder en/of kyker nouer met die alledaagse en bekende wêreld in verbinding gebring (vgl. Detweiler 2005b:98; Hogan 2008:147).

Is die gebruik van PowerPoint in die vertoning van visuele beelde op 'n skerm binne die erediensruimte, as deel van die prediking, egter noodwendig in wese visuele prediking? Afhangende van hoe die prediker dit opstel en aanwend kan PowerPoint-aanbiedings nog steeds 'n linkerbrein-gedomineerde funksie verrig wat die menslike verbeelding latent laat en die denkbeeld-dimensie in 'n sluimerende status laat verkeer. Denison (2006:25) noem dit '... a nice picture with a theme'. PowerPoint-aanbiedings wat op 'n liniêre, didaktiese, diskoersiewe en verklarende wyse gestruktureer word om bloot punte van die preek te onderstreep (Hogan 2008:146; Lischer 2005:25; Smith 2006) of bloot die teksvers van die preek te vertoon, druk steeds die linkerbreingefokusde, intellektuele literêre denkpatroon van die modernisme uit (Denison 2006:25; vgl. Sweet 1999:207). Wat vandag nodig is, is PowerPoint-aanbiedings wat oor die metaforiese corpus callosum na die regterbreindimensie van kreatiewe mitologiese beeldende denke kan reik (Denison 2006:26). Om die boodskap binne beelde en uitbeeldings te verpak word 'n kragtige appèl tot 'n heel ander dimensie van die menslike psige gemaak (Johnston 2001:166).

Hoe maak die prediker hierdie wesenlike sprong van die linkerbrein-denke na die heelbrein-holisme waar beeld heers? Anders gestel, hoe beweeg die prediker van skyfievertonings na beeldpreke? (Jensen 2005:135). Volgens Jensen (2005: 127, 135) verskuif die preek vanaf 'n denke in idee na 'n denke in beeld wanneer die beeld sélf die organiserende sentrum van die preek word (vgl. Burke 2005:76; Jensen 2005:127, 135).

In die volgende paragrawe word praktiese riglyne aan die hand van bepaalde omskrywende terme neergelê waarmee hierdie kommunikatiewe verskuiwing na die visuele beklemtoning aangedui word. Elkeen van hierdie praktiese riglyne wil die prediker tot visuele prediking begelei.

\section{Nie-liniêr}

Groot dele van die lewe is nie-liniêr (vgl. Hogan 2008:147; Niemandt 2007:116). Allermins is dit chaoties, maar nie noodwendig altyd vooraf beplan en logies gestruktureerd met verwagte uitkomste waar die hoorder en/of kyker presies weet wat kom en met sekerheid vooruit kan antisipeer nie (vgl. Niemandt 2007:116). Geen mens ken immers die lewe 
so nie, en prediking word wêreldvreemd en selfs vervelig wanneer dit op hierdie wyse funksioneer (Beach 2004:187).

PowerPoint-aanbiedings kan treffend aansluit by daardie nie-liniêre verloop van die lewe waaraan die gemeente so goed gewoond is, deur soms die gedagtegang van die preek te swaai of te onderbreek ter wille van nuwe fokus, hernieude konsentrasie of verrassing, en selfs veelvlakkige kommunikasie (Jensen 2005:128; vgl. Johnston 2001:109; Van Tonder 2006:103). Veelvlakkige kommunikasie kan byvoorbeeld tot stand kom wanneer die PowerPointaanbieding parallel met die preek 'n tweede storielyn vorm. Terwyl die prediker die Bybelverhaal vertel of lees, verbeeld die visuele uitbeelding 'n hedendaagse verwante verhaal wat gelyklopend afspeel (Jensen 2005:128; vgl. Sweet 1999:163).

Sweet (1999:207) praat in hierdie verband van stapelstories of opgehoopte narratiewe waar verskillende verhale of verlope in en uit van mekaar in 'n spiraalvormige sirkel beweeg (vgl. Van Tonder 2006:103). Waar die gedrukte medium die liniêre denkpatroon van logiese verloop geskep het, skep die elektroniese visuele medium 'n meer natuurlike, organiese en minder enkelvoudige denkpatroon (Sweet 1999:207). Hierdeur word 'n beweeglike hiperteks met verskeie onderliggende tekste geskep.

\section{Beeldgedrewe}

Aan die een kant gaan dit by die beeldgedrewe prediking om PowerPoint-aanbiedings wat nie woord uitbeeld nie, maar bééld (Mathewson 2007:1). Uiteraard kan dit steeds met die tipies modernistiese denkpatroon in een preek gekombineer word om die verskeidenheid van mense in die gehoor aan te spreek, of andersins kan dit preek na preek afgewissel word ter wille van verskillende genres of gehoor-fokusse (vgl. Jensen 2005:105).

Aan die ander kant gaan dit by beeld-gedrewe prediking om PowerPoint-gedrewe prediking in plaas van blote PowerPoint-ondersteunde prediking (vgl. Mathewson 2007:1). Eersgenoemde verskil van laasgenoemde in dié sin dat die liniêre gedagtegang van die redelike feitelike gegewens vervang word met beelde wat gedagtes en gewaarwordinge oproep, wat tot 'n nuwe geestelike bewussyn aanleiding gee waar 'n appèl op die logika van die menslike verbeelding gemaak word (vgl. Jensen 2005:135). Beeldgedrewe aanbiedinge vervul 'n liturgiese rol eerder as 'n blote kommunikatiewe rol. Liturgiese beelde speel in hierdie sin 'n selfstandige verkondigingsrol wat essensieel tot die prediking bydra, en selfs met tye die prediking kan wórd (vgl. Denison 2006:25). Liturgiese beelde kan bepaalde liturgiese elemente uitlig of 'n besondere liturgiese oomblik skep waar die beeld of uitbeelding kragtig tot die gemeente spreek (Jensen 2005:140).

\section{Eenvoud}

'Minder is meer', bly ook hier die homileet se wagwoord (Jensen 2005:122; Mathewson 2007:3). Hoe meer beeldende skyfies in die aanbieding gebruik word, hoe groter word die inligtings-interaksie. Aan die ander kant is die visuele generasie wat deel van die gemeente uitmaak, gewoond aan die massamedia se visuele tegnieke van kits-kommunikasie waar beelde selfs met tiendes van sekondes oor die skerm flikker (Sweet 1999:205). Sweet (1999:203) onderstreep dat die menslike denke juis vinniger op beeld as op logika reageer.

Tog kan 'n goeie saak uitgemaak word vir eenvoudiger visuele uitbeeldings wat retensie en emosionele interaksie, waarvoor meer tyd en eenvoud benodig word, kan verhoog (Johnston 2001:63). Rondom een goed-gekose visueelaangrypende en kragtige beeld of video-insetsel kan 'n hele preek ontwikkel (vgl. Jensen 2005:135, 137, 140) - sónder om die boodskap of teks enigsins te oorweldig (vgl. Lischer 2005:110). Wanneer' $n$ preek rondom een enkele beeld gebou word, kan dit baie dramaties beklemtoon word deur daardie beeld deur die hele preek te vertoon (Jensen 2005:140). 'n Welgeplaasde visuele uitbeelding kan die gemeente begelei na ' $n$ dieper denkbeeldige interaksie en hulle na die teks neem eerder as andersom (vgl. Beach 2004:231; Mathewson 2007:3).

Ook wat die gebruik van video-insetsels betref, geld die 'minder is meer' beginsel steeds volledig. 'n Sinvolle gemiddelde tyd vir die vertoning van ' $n$ videosnit sal tussen vier en ses minute wees (Jensen 2005:103). Indien die videosnit te kort is, kan dit eerder steurend op die kommunikasieproses inwerk, terwyl 'n langer videosnit mense se belangstelling kan verloor en irritasie tot gevolg kan hê.

\section{Stilte}

'n Uiters effektiewe wyse om 'n geprojekteerde beeld binne 'n meditatiewe proses van gefokusde nadenke te gebruik waar die beeld toegelaat word om tot die kyker te spreek, is om 'n stiltemoment binne die erediens te skep waar alleen die geprojekteerde beeld die fokus vorm. Binne die stilte geskied oordenking wat deur middel van beeld opgeroep word en waardeur die kyker toegang tot sy of haar dieper belewingpsige verkry (vgl. Denison 2006:26). Nog 'n variasie hiervan geskied binne die kontemplatiewe erediens waar 'n goed-gekose en -opgestelde visuele aanbieding die plek van die liturg vir daardie spesifieke geleentheid volledig inneem (vgl. Jensen 2005:135). So word die gemeente deur 'n stilwordproses geneem tot oordenking van 'n bepaalde Skrifgedeelte en uiteindelik diepgaande aanbidding deur middel van gebedsliedere of stilgebed.

Nooit gaan dit egter daarom dat die visuele aanbieding die liturg word of vervang nie - eerder is dit die liturg wat deur middel van hierdie visuele medium die erediens en die ontmoetingsproses begelei. Wanneer die liturg op hierdie wyse terugstaan, kan 'n kragtige Goddelike moment tot stand kom (vgl. Beach 2004:207, 215).

'n Verdere dimensie van stilte kan visuele stilte genoem word. In 'n konteks waar die visuele sintuig van die mens met inligting oorweldig word (vgl. Lischer 2005:12, 13; Sweet 1999:112,167), het mense met tye ook 'n beeldstilstand nodig. 'People are desperate for simplicity' (Sweet 1999:168). 
'n Goeie balans moet daarom tussen visuele stimulasie en visuele stilte gevind word (vgl. Lischer 2005:12). Sulke momente van visuele stilte kan binne die erediens ingebou word deur op gegewe oomblikke géén visuele stimulasie toe te laat nie ter wille van innerlike nadenke of 'n na-binnekyk-geleentheid, of minstens die visuele stimulasie tot so 'n mate te vereenvoudig dat ' $n$ visuele rusmoment daardeur tot stand kom (vgl. Jensen 2005:103; Lischer 2005:5).

\section{Teksverheldering}

Beeld se bedoeling bly steeds om die teks waarop in die preek gefokus word op te helder en daarom nooit 'n doel opsigself nie (vgl. Jensen 2005:138; Lischer 2005:109-110; Smith 2006). Selfs al wórd die beeld die 'teks' binne die preek en 'spreek' dit selfstandig tot die kyker, moet dit áltyd nog die Woord uitbring of belig - dit impliseer dat die beeld kommunikatief sterk genoeg moet wees om steeds die Woord aan die spreek te kry (Jensen 2005:140).

Diep-sprekende beelde verhelder die evangelieboodskap in mense se gees en begelei hulle tot ' $n$ dieper interaksie met die teks (vgl. Beach 2004:230). Wanneer die visuele beeld mense na die teks begelei word daar met nuwe oë en groter openheid na die teks gekyk, en stimuleer die beeld geestelike groei deur Goddelike inspraak.

In die geval waar die beeld die teks vir daardie geleentheid ís, moet die prediker verseker dat die beeld die Bybelse inhoud duidelik en sonder kompromie oordra. God se Woord moet in alle gevalle steeds suiwer geskied selfs wanneer dit deur beeld eerder as woord na die menslike bewuste kom (vgl. Jensen 2005:137; Lischer 2005:111)

\section{Verweefdheid}

Enige beeld wat geprojekteer of andersins visueel aangebied word, moet nou met die teks en die res van die boodskap verweef word (Beach 2004:242; Smith 2006). Nie alleen moet die genre van die teks en die genre van die beeld komplimenterend op mekaar inwerk nie, maar die visuele uitbeeldings moet kan inskakel sonder dat lywige verduidelikings of begripspronge nodig is (vgl. Van Tonder 2006:106).

Natuurlik beteken dit nie dat verrassing, afwisseling, non-liniêre verskuiwinge of veelvlakkige kommunikasie hierdeur weggeneem word nie, solank die beeld telkens korreleer met die groter konteks van die kommunikasie-reis (Johnston 2001:160). 'n Duidelike konneksie tussen die beeld wat vertoon word en die woorde wat dit vergesel speel 'n groot rol in die effektiewe kommunikasiegebeure (Jensen 2005:121).

\section{Kwaliteit}

Geprojekteerde beelde of video-insetsels moet ten alle tye van hoë gehalte en sigbaarheid getuig, indien dit sprekend tot mense moet wees (vgl. Beach 2004:152). Kunstige visueelstimulerende en visueel-strelende beelde van hoogstaande kwaliteit spreek die sintuie sterk aan en ondersteun die boodskap sowel as die proses waartoe die prediker die hoorder en/of kyker oproep.

Sodra die beginsel van uitnemendheid of voortreflikheid ook in die voorbereiding van die visuele uitbeelding ernstig opgeneem word, sal dit meebring dat die hoorder en/of kyker ook die kommunikatiewe bedoeling daarmee sowel as die boodskap daaragter ernstig opneem (vgl. Beach 2004:140, 152). Saam met die kwaliteit van die visuele voorstelling is die gehalte van die tegnologiese aanbieding van dieselfde belang (Jensen 2005:121).

Iemand wat visuele tegnologie binne die erediens en prediking aanwend, moet persoonlik daarmee gemaklik wees en dit vooraf inoefen en toets. Geen groter boodskap van onvoorbereidheid en onprofessionaliteit word uitgedra as wanneer die prediker of liturg binne die aanbieding moet begin rondskarrel omdat die tegnologie hetsy nie behoorlik vooraf getoets is, of die aanbieding nie vooraf op die vertoonskerms deurgegaan is nie.

In aansluiting hierby skryf Beach (2004:150): 'Of all people, Christians should be addicted to quality and integrity in every area, not looking for excuses for second-best. We must demand higher standards'. Enige vrywilliger wat by die tegniese en visuele bediening van die gemeente betrokke raak, moet duidelik bewus wees van die hoë standaard wat vereis word, en moet ook bereid wees om na behore daarvoor opgelei te word (vgl. Jensen 2005:107).

Deel van die keuse van kwaliteit uitbeeldings behels ook ' $n$ smaakvolle, sensitiewe en fyn polities-korrekte aanvoeling (vgl. Fry Brown 2008:110; Jensen 2005:122). Wanneer uitbeeldings negatiewe assosiasies by mense oproep, of kontroversiële en onvanpaste ervarings tot gevolg het, sluit dit die kommunikasiekanaal dig toe (vgl. Jensen 2005:101). Indien die prediker deur die beeld egter doelbewus reaksie wil uitlok, moet hy of sy dit goed binne 'n konteks plaas of met sensitiwiteit verduidelik.

\section{Illustrasies}

Ten spyte van die kommunikatiewe tegnologie wat vandag tot die prediker se beskikking is, bly die eenvoudige uitbeelding deur middel van die een of ander fisiese hulpmiddel of rekwisiete steeds 'n kragtige visuele boodskap (Beach 2004:236; vgl. Lischer 2005:119). Op die verhoog of binne die erediensruimte kan konkrete uitbeeldings uiters persoonlik beleef word (vgl. Jensen 2005:102).

Effektiewe lering kan hierdeur plaasvind omdat die assosiasie van die illustrasie na die teks en die boodskap deurgetrek kan word (Beach 2004:237; vgl. Lischer 2005:109). Behalwe dat die illustrasie die geheue-skakel na die teks en boodskap word, stimuleer dit ook ontvanklikheid en prikkel dit die belangstelling wat leer en groei tot gevolg het (vgl. Beach 2004:239).

Lischer (2005:110) wys op die gevaar van die preek-illustrasie, wanneer dit neig om die preek oor te neem en die aandag 
van die evangelie af te trek. Illustrasies moet die boodskap verhelderend verpak en daarom telkens goed deurdag wees voordat dit binne 'n preek aangewend word (vgl. Lischer 2005:111).

\section{Afwisseling}

Een van die grootste geheime van visuele prediking, net soos in die geval van oratoriese prediking, is in afwisseling geleë. Natuurlik gaan dit nooit om die afwisseling opsigself nie, maar liewer om die kreatiewe verskeidenheid wat elke preek 'n unieke en onvergeetlike ervaring maak (vgl. Jensen 2005:104). Selfs wanneer video-insetsels of PowerPointaanbiedings weekliks op dieselfde wyse aangewend word, kan dit stereotiperend word en die kragtige kommunikatiewe impak verloor (vgl. Hogan 2008:135).

\section{Visuele uitbeeldingspreke}

Visuele uitbeeldingspreke verskil van visuele beeldpreke op daardie wyse dat eersgenoemde visuele uitbeelding gebruik om 'n boodskap oor te dra. Waar die beeldpreek van fisiese geprojekteerde of mensgemaakte beelde op 'n plat oppervlakte gebruik maak, wend uitbeeldingspreke fisiese visuele metafore aan: metafore wat op 'n konkrete wyse deur middel van ' $n$ sigtelike uitbeelding in die erediensruimte of op die verhoog uitgebeeld word (vgl. Beach 2004:169, 221, 236-239).

Narratiewe prediking of verhalende prediking is een van die mees besondere kommunikatiewe instrumente vir post-moderne prediking (Collison 2000:2; Jensen 2005:127; Lischer 2005:94; Nel 1996:129). Ongelukkig verstaan 'n groot hoeveelheid van predikers en teoloë onder narratief alleen die mondelinge of skriftelike verhaal soos dit oor die jare binne die modernisties-gedrewe homiletiek beskryf en aangewend is (Lischer 2005:41, 91; vgl. Jensen 2005:135).

Drama, dans, mimiek en poppespel as deel van die genre van die uitvoerende kuns is egter ook volwaardige visuele narratiewe wat sinvol met die prediking geïntergreer kan word (Beach 2004:9; vgl. Vos \& Pieterse 1997:129). Hier is die uitsluitlike verskil dat dit nie op 'n mondelinge wyse soos die denkbeeldige narratief oorgedra word nie, maar eerder op liggaamlike wyse as deel van die uitvoerende kunsgenre (vgl. Vos \& Pieterse 1997:128).

Die erediens is reeds deurspek van liggaamsbewegings soos die gewyde houding en die buig van hoofde onder gebed (Vos \& Pieterse 1997:129). Volgens Barnard is die mens 'n eenheid in sy of haar betrokkenheid binne die erediens, en speel die dimensie van die liggaamlike hierin 'n sentrale rol (Barnard 1995:219).

In die volgende paragrawe word na hierdie dinamiese en opwindende bedieningsmediums gekyk met die doel om praktiese riglyne vir die sinvolle integrering daarvan met die prediking op te stel (vgl. Vos \& Pieterse 1997:130) wat predikers kan help om met vertroue van hierdie kragtige visuele uitbeeldings gebruik te maak.

\section{Uitvoerende visuele metafore}

Tot voor die reformasie was teater 'n doodnormale deel van die kerk se visuele geloofsuitdrukking binne die liturgie (Comby 1985:153). Hierdie teaterproduksies is op die sypaadjies voor kerkgeboue, en selfs binne erediensruimtes aangewend (Comby 1985:153). Ikonoklasme het tot gevolg gehad dat ook hierdie uitbeeldingstyl vir die kerk verlore gegaan het (vgl. Detweiler 2005b:98).

Prediking kan vandag weer goed uitgebou word deur die sinvolle aanwending van oudiovisuele kunsvorme soos dramas, mimieke, danse en poppespele, wat juis die visuele styl van prediking ondersteun (Jones 2001:21). Prediking binne die post-moderne konteks is volgens Jones (2001:21) minder woord-georiënteerd, met ander woorde minder klem word op die verbale geplaas en ander mediums word nét so effektief en selfs meer effektief aangewend om daardie selfde boodskap te kommunikeer (Hogan 2008:147; vgl. Campbell 1981:20).

In 'n visueel-gedrewe konteks kan uitvoerende visuele uitbeeldings kragtige momente van verkondiging en belewing skep (vgl. Beach 2004:219). Immers bevind die post-moderne mens homself en haarself in 'n multisensoriese kultuur en kan dus moeilik ánders aangespreek word (McDougal 2009:4; Van Tonder 2006:109). So verstaan, is oudiovisuele uitvoerende kunsvorme nié iets uit die bose of blote vermaak nie (vgl. Blackwood 2009a:1), maar 'n Godgegewe instrument waarmee mense met die evangelie bereik kan word en daarom heel vanpas binne die erediens as verkondigings- en aanbiddingsgebeure (vgl. Beach 2004:10, $211,242)$.

\section{Gemeentespanne}

Elke gemeente het kunstenaars en akteurs wat wag om ontdek te word (Beach 2004:261). Hierdie artistieke mense kan 'n geweldige bydrae tot die erediens en preek lewer indien hulle uitgenooi en uitgedaag word om hulle kunstige vermoëns aan te wend vir iets wat ewigheidswaarde toevoeg en die potensiaal besit om tien teen een die grootste avontuur van hulle lewe te word (Beach 2004:261).

'n Dramaspan, mimiekspan, dansspan en poppespelespan (naas die musiekspan, tegniese span en videospan) skep nie net geleentheid vir verrykende bediening en betrokkenheid nie, maar ook vir persoonlike groei en gemeenskap met ander gelowiges (Beach 2004:261). Verby is die tyd dat die dominee en orrelis die erediens alleen kon aanbied (vgl. Beach 2004:9). Gemeentelede raak met hulle besondere geestelike gawes betrokke by liturgiese handelinge en verkondiging (Niemandt 2007:109).

Natuurlik bly die geheim vir sukses dat die spanne wat hierdie kunsvorme binne die erediens beoefen, duidelik ingelig moet wees oor die spesifieke bydrae wat hulle tot die boodskap moet lewer sodat dit werklik effektief by die preek kan inskakel, en sodoende 'n kragtige verkondigingsrol kan speel (Van Tonder 2006:109). Gereelde visionering en 
bemoediging behou die motivering en toewyding van spanne (Beach 2004:40; Jensen 2005:107). Deurlopende leierskap is ' $n$ noodsaaklikheid om die spanne bymekaar en gefokus te hou.

Die hoë standaard en artistiese integriteit waarmee hierdie kunsvorme aangebied moet word, kan nooit genoeg beklemtoon word nie (Van Tonder 2006:109; vgl. Beach 2004:208; Warren 2006). Om hulle rol binne die erediens behoorlik te verstaan, is dit noodsaaklik om hierdie spanne te betrek by die beplanning deur weeklikse beplanningsessies te hou (Beach 2004:53, 73).

Gereelde dinkskrums in samewerking met die kreatiewe spanne skep selfs groter kreatiwiteit rondom eredienste en preke (Beach 2004:178; Young 2006). Terugvoer en evaluasie waarby die spanne betrokke is bevorder ook groei en kwaliteit (Beach 2004:106, 113).

\section{Selfverduideliking}

Stevenson (1981:42) waarsku teen die oordrewe poging van predikers om altyd alles te wil verduidelik (vgl. Burke 2005:86). Veral wanneer dit by die uitvoerende kunste kom, is die genre van so aard dat dit hetsy selfverduidelikend is en voldoende vleis het om op eie meriete te steun (Van Tonder 2006:107) of andersins oop is vir interpretasie-moontlikhede wat juis van dit kuns maak (Romanowski 2007:18).

Ruimte moet altyd gelaat word vir die visueel intelligente kyker van vandag om tot eie konklusies te kom (Johnston 2001:160). Massamedia en die populêre kunste het die visuele kyker uitmuntend geleer om geweldige komplekse betekenisspronge te maak en inhoudelike waarde toe te voeg, wat van die hedendaagse kyker 'n uiters bekwame visueelgeletterde op die gebied van die visuele kommunikasie maak.

\section{Integriteit}

Korrelasie met die werklikheid skep by die post-moderne hoorder en/of kyker wat soekend is na egtheid, die gevoel dat hy of sy met vrymoedigheid na die uitvoerende visuele uitbeelding kan kyk (Beach 2004:210). Prekerigheid en manipulasie in dramas, mimieke, danse en poppespele moet daarom ten alle koste vermy word (Beach 2004:210).

Simplistiese uitkomste verdring die integriteit van die kunsvorm omdat die hoorder en/of kyker geensins uit persoonlike ervaring daarmee kan assosieer nie. Misrepresentasie van die lewe dra die beeld van oneerlikheid en valsheid aan die post-moderne mens oor (Beach 2004:210). Geloofwaardigheid open kommunikasiekanale en mense se harte vir die dieperliggende boodskap (vgl. Lischer 2005:126).

Modernistiese mense woon eredienste by om die vraag te beantwoord: 'Is dit waar?' Post-moderne mense woon eredienste by om die vraag te beantwoord: 'Is dit eg?' (Sweet 1999:215). Sodra die hoorder en/of kyker iets van sy of haar eie belewing van die lewe in die visuele voorstelling sien, skep dit openheid en ontvanklikheid (Johnston 2001:70).

\section{Gebruik van kuns}

Kuns is die visuele voortsetting van God se skeppingswerklikheid deur middel van die menslike verbeelding (vgl. Niemandt 2007:114). Vandaar kan dit God besonderlik verheerlik (Beach 2004:165). Ruimte vir die kreatiewe uitingsvorme van die kunste kan sinvol binne die erediens geskep word deur byvoorbeeld een of ander genre binne die liturgie in te bou soos om te skilder of te skryf (Niemandt 2007:114).

Deur byvoorbeeld 'n kunstenaar te gebruik om 'n pottebakkers-kunswerk op die verhoog te skep terwyl die prediker daaroor preek, kan 'n geweldige en onvergeetlike impak op al die sintuie van die hoorder en/of kyker maak en die teks kragtig huis toe dryf (Beach 2004:237).

Musiek en sang is net sulke magtige sleutels van die verbeelding waarmee mense beweeg, bedien en geraak kan word, en kan besonderlik binne die prediking as ondersteunend tot die boodskap of 'n bepaalde liturgiese ervaring gebruik word (Beach 2004:9; vgl. Van Tonder 2001:53; Vos \& Pieterse 1997:57).

Wanneer die prediker interaksie met sy of haar eie kreatiwiteit het, kan daardie kreatiwiteit natuurlik nie sonder enige grense op die gemeente losgelaat word nie. Beach (2004:208) bied daarom vier belangrike vrae wat telkens gevra moet word wanneer in die kreatiewe proses ingegaan word:

- 'Beweeg hierdie simbool, metafoor, kunsvorm, ritueel my?'

- 'Is dit teologies suiwer en Bybels waar?'

- 'Het dit kunstige integriteit?'

- 'Is dit smaakvol?'

Positiewe beantwoording van hierdie vier vrae sal outomaties kunstige waardigheid en kommunikatiewe integriteit aan die visuele uitbeelding verleen en die gemeente positief daarop instel (vgl. Beach 2004:208).

\section{Visuele verbeeldingspreke}

'n Visuele verbeeldingspreek verskil van die visuele beeldpreek en die visuele uitbeeldingspreek op daardie wyse dat dit die menslike verbeelding oproep en daarmee kommunikatiewe interaksie het (vgl. Denison 2006:21; 26). Hiervoor word geen fisieke visuele uitbeelding aangewend nie, maar wel relevante metaforiese taal wat dramaties, kunstig en beskrywend gebruik word (vgl. Jensen 2005:137; Lischer 2005:104-105). Vanuit hierdie verbeeldingspel ontwikkel diepere insigte in die menslike situasie wat uiteindelik die teks open en 'n persoonlike appèl op die hoorder en/of kyker plaas (vgl. Denison 2006:9).

Enigeen wat oor die kerk en die teologie wil nadink, moet dit met verbeeldingrykheid kan doen, want die Bybel is niks anders as kuns nie (Niemandt 2007:112). Verbeelding beteken om iets tot bestaan op te tower wat nog nie bestaan nie (Troeger 2007:60). Verbeelding het egter die roumateriaal nodig wat dit kan aktiveer. Sulke roumateriaal verskaf aan 
die prediker die moontlikhede waarmee die gemeente op 'n emotiewe geloofsreis begelei kan word.

Stories en verhale is juis sulke roumateriaal (vgl. Burke 2005:75; Johnston 2001:155). Inderdaad is dit nie die enigste roumateriaal waarmee die verbeelding aangegryp kan word nie. Visuele kuns, musiek en visionêre saamdroom is maar nóg enkele vorme waarmee die verbeelding in beweging kan kom (Jensen 2005:87; vgl. Niemandt 2007:113). Uitvoerende kuns en uitbeeldende kuns spreek ook net so goed tot die verbeeldingsdimensie van die mens.

Tog bly dit die narratief wat sonder enige ander hulp as die blote gesproke of geskrewe woord, tot die diepste dimensies van die menslike verbeelding kan deurdring deur die mens binne-in die storie en daarmee binne-in die leerervaring te bring (vgl. Lischer 2005:92; Robinson 2006; Zander 2006). Narratiewe plaas mense op die vlak van gedeelde menslikheid (Johnston 2001:155).

Waar die verhaal vir die prediking aangewend word, gaan geloof meer oor '... recognition than cognition' (Jensen 2005:127). Hoorders en/of kykers sien hulleself en hulle eie lewens in die storie. Ook die implikasies daarvan vir hulle lewens sowel as die aanpassings waarvan hulle daardeur bewus raak, spring uit die verhaal na vore (Jensen 2005:127).

Om die narratiewe preek te laat lewe en 'n daadwerklike impak te laat hê, speel die verbeeldingskrag 'n kritiese rol (Carter Florence 2008:121; Denison 2006:43). Aldus Robinson (2006) speel die narratief op beide speelvelde van sowel die linkerbrein as die regterbrein - die linkerbrein kom in spel om die storie te verstaan; die regterbrein kom in spel om die storie te verbeel (Robinson 2006).

Vir die verbeelding van die gemeente om binne die preek ontsluit te word, moet ' $n$ deur geopen word vanaf die linkerbrein-logika na die regterbrein-beeldende dimensie van die menslike psige (Miller 2006). Een van die kragtige wyses waarop hierdie deur oopgesluit kan word is deur die narratiewe medium (vgl. Lischer 2005:100), en met die kunstige aanbieding daarvan, kan die deur wyd oopgestoot word sodat die mens op 'n regterbreinvlak aangespreek kan word (Burke 2005:75; vgl. Denison 2006:43).

Hieronder volg enkele praktiese riglyne vir die prediker wat hierdie brug na die post-moderne mens se verbeeldingsdimensie wil bou deur van die narratief en metafoor gebruik te maak.

\section{Gebruik van narratiewe}

Aanwending van helder beeldspraak in die narratiewe prediking is 'n noodsaaklikheid (Johnston 2001:171; vgl. Lischer 2005:119). Vae veralgemenings en dorre, harde woorde konnekteer nie met mense nie en misluk daarin om denkbeelde te help vorm (Johnston 2001:159).

Woord-ekonomie gekombineer met weldeurdagte en duidelike beskrywings stimuleer wel die menslike verbeelding (Johnston 2001:159). Spanning kan sinvol in die storie gebruik word deur byvoorbeeld die uitkoms of ontlonting van die verhaal uit te stel (Johnston 2001:158; Young 2006). Spanning kweek afwagting en afwagting kweek ontvanklikheid (Miller 2006).

Belangstelling moet altyd deur die storie geprikkel word. Mense het ' $n$ diepe behoefte aan inspirasie en hoop (Lischer 2005:96). Deur die narratief met opwinding en interessante beskrywings aan te bied kan die belangstelling geprikkel word en mense meer deelnemend begin luister en kyk (Miller 2006).

Om die storie in te lei, is 'n broodnodige kuns wat aangeleer moet word indien die verteller wil hê dat die storie mense moet saamneem en veral na die boodskap van die preek moet begelei (Johnston 2001:159; vgl. Hogan 2008:142). 'n Inleiding kan die verhaal maak of breek (Hogan 2008:142; vgl. Lischer 2005:97 ). In plaas daarvan om byvoorbeeld te begin met "n Man stap in 'n winkel in ...' kan die storie die hoorder en/of kyker sterker vasgryp deur dit te begin met 'Almal het nuuskierig opgekyk toe dié vreemde karakter met sy sakkerige klere instap ...'

'n Retoriese vraag kan ook 'n goeie inleiding skep: 'Het jy ook al gevoel of jy ...?' (Johnston 2001:158). Sodra die prediker op hierdie wyse met ' $n$ verhaal of 'n inleiding tot 'n preek begin, voer dit die hoorder en/of kyker mee. Onmiddelik skep dit 'n verwagting dat die prediker die moeite werd is om na te luister omdat hy of sy so goed verstaan en aansluiting vind by die omstandighede van die hoorder en/of kyker (vgl. Hogan 2008:140). Retoriese vrae skep emosionele verbinding tussen die prediker en die hoorder.

\section{Gebruik van metafore}

Volgens Vos is metafore die vonke wat deur die menslike verbeelding aangesteek word (Vos 2007:22). Verbeelding en metafoor loop dus altyd hand aan hand. Metafore word gebruik om die mens te help om die onbekende en onverstaanbare te verken en te verstaan (Vos 2007:23).

Daarom is die Bybel so vol van metaforiese taal. Bybelse metafore beskryf immers ' $n$ dimensie só vreemd en ver verwyderd van die alledaagse leefwêreld van die mens, dat dit in geen ander taal as metaforiese taal uitgedruk kan word nie. Deur metafore te gebruik wat die alledaagse leefwêreld nader aan die Goddelike wêreld (rééds 'n metafoor) bring, verkry die mens toegang tot hierdie tot dusver ontoeganklike wêreld (vgl. Vos 2007:23).

Omdat metafore sulke kragtige sleutels is waarmee die geloofservaring oopgesluit kan word, is dit 'n onmisbare instrument vir elke homileet wat binne die hedendaagse samelewing wil preek. Predikers sal daarom moet leer hoe om kreatief met die Bybelse metafore om te gaan, maar ook hoe om nuwe lewende metafore te skep wat tot die hedendaagse mens spreek (Beach 2004:181; Detweiler 2005a:82; vgl. Lischer 2005:119). 
Kreatiwiteit ontstaan in 'n kombinasie van God as die Skepper wat die prediker op 'n kreatiewe geloofsreis saamneem (die kén van God) en die prediker wat sy of haar gehoor en omgewing verstaan (die ken van die konteks - Johnston 2001:64; Tubbs Tisdale 2008:75). Goddelike inspirasie geskied alleen in 'n lewende relasie tot God (Beach 2004:137).

Om metafore te skep wat kragdadig impakteer, sal die prediker met tye bereid moet wees om groot te waag (Beach 2004:175). Per geleentheid sal die prediker selfs gelief moet neem om 'n metafoor te skep wat aanvanklik uitstekend lyk, maar binne die erediens eintlik geheel en al misluk (Beach 2004:180).

Geen metafoor of vergelyking is ooit volledig toepaslik nie, omdat dit altyd ' $n$ beperkte menslike beeld is wat ' $n$ Goddelike waarheid wil oordra (vgl. Prokes 1996:xiv). Predikers moet altyd daarteen gemaan word om nie die beeldspraak allegories te ver te wil neem nie, aangesien dit die geloofwaardigheid daarvan kan beïnvloed.

\section{Gebruik van rituele}

Niemandt (2007:115) maak daarop attent dat eietydse rituele 'n wonderlike wyse is waarop geloofswaarhede op 'n kreatiewe manier uitgedruk kan word. Behalwe dat dit deelname en interaksie bevorder, en die totale mens daarby betrek (Buitendag 2009:228), skep dit ook herinneringe en geloofsbakens waarmee mense se geloof versterk kan word (Beach 2004:170). Rituele wat betekenisvol en dramaties gevul is, nooi mense tot deelname waarin hulle harte volledig uitgestort kan word (vgl. Buitendag 2009:228; Long 2001:88).

Rituele is die taal van die post-moderne mens en predikers moet hierdie taal leer praat sodat momente geskep kan word waar God op 'n dieper vlak as blote taal kan spreek (Beach 2004:223; vgl. Vos \& Pieterse 1997:120-121). Wanneer mense binne die erediens en selfs die preek by die punt gebring word waar hulle self ook iets konkreet en aktief doen, skud dit hulle uit hulle passiwiteit en open dit al hulle sintuie vir 'n unieke leerervaring (Zander 2006).

Een geheim vir' $n$ ritueel wat mense werklik kan aanspreek en nog vir jare lank 'n geestelike baken van geloofsversterking kan wees, is om dit met groot omsigtigheid te kies. Sodra mense in ongemaklike posisies geplaas word, of onwaardige rituele moet uitoefen, het dit negatiwiteit tot gevolg en word die groeigeleentheid daarmee gestuit. Rituele moet met die waardigheid en smaakvolheid wat binne die erediens tuishoort, aangewend word en ook die erediensganger respekteer (vgl. Long 2001:88).

\section{Samevatting}

Hoewel daar in hierdie artikel op die hedendaagse konteks gefokus is, bly die Christelike uitkyk nòg modernisties nòg post-modernisties (Johnston 2001:9). 'Christianity cannot wholly embrace either modernity or post modernity, yet it must learn lessons from both; it must vigorously oppose many features of philosophical pluralism, without retreating to modernism' (Johnston 2001:15).
Daarmee word nie bedoel dat die Christelike uitkyk verhewe bó kontekste onaantasbaar staan nie (vgl. Tubbs Tisdale 2008:75), maar wel dat die wese van die inhoud van die evangelie van Jesus Christus nooit verander nie. Jesus se goeie nuus is immers steeds dieselfde, hoewel die vraagstukke van die hedendaagse mens wél radikaal anders as voorheen is (vgl. Denison 2006:xi; Tubbs Tisdale 2008:75).

Eerder beteken die bostaande stelling dat die Christelike uitkyk aanpasbaar is en telkens transformerend kan inskakel by die konteks waarbinne dit Goddelike transformasie moet bewerkstellig (vgl. Sweet 1999:72). Kritiese onderskeiding bly die hart van die inkarnasionele roeping van die Christendom (Johnston 2001:11; vgl. Romanowski 2007:14).

Prediking binne vandag se konteks is sekerlik nog lank nie 'n uitgedateerde kommunikasiemedium nie (vgl. Johnston 2001:8; Lischer 2005:45). Wat wél iets van die verlede is, is die modernistiese kommunikasiestyl van die prediking: die verpakking daarvan binne 'n oratoriese rasionele lesing en liniêre toespraak wat tot mense spreek, maar mense nie meer aanspreek nie (Burke 2005:75; Garrety 2005:90; Hogan 2008:147; vgl. Johnston 2001:9).

Prediking sal net soos die evangelie waarvan dit getuig, nooit deur die strominge van die tyd meegesleur kan word soos in die era van die modernisme juis die geval was nie. Wanneer dit wél gebeur, word die prediking uitverkoop en verloor dit relevansie en impak sodra die tydstroom in 'n nuwe rigting swenk (Denison 2006:xi).

Vir gans te lank was prediking geassosieer met kategismelering wat vir die gelowige tot nut en waarde was, gegiet binne 'n konteks van gedeelde taal waar almal 'n redelike goeie begrip van die verpakking sowel as die inhoud gehad het (vgl. Lischer 2005:96). Vandag staan die homiletiek voor die dilemma van vervreemding met die konteks waarbinne dit arbei (vgl. Johnston 2001:9; Sweet 1999:45):

We can no longer assume that our preaching takes place within a more or less Christian culture. The great narratives of JudeoChristian belief, the pivotal stories of the Bible's characters, the epoch of the life and ministry of Jesus Christ, either are not known or do not carry the meaning-making significance they did to previous generations.

(Johnston 2001:15)

Mense sal vandag opnuut geleer moet word hoe om die wêreld vanuit 'n Christelike verwysingsraamwerk te benader.

Hedendaagse prediking sal daarom weer moet lyk soos die prediking in die tyd van die Nuwe Testament: missionêre preke wat die goeie nuus van Jesus Christus in vreemde wêrelde indra waar Hy nog geheel en al onbekend en selfs onwelkom is (vgl. Johnston 2001:10). Net soos geen ware sendeling ooit die arbeidsveld sal binnetree voordat hy of sy nie 'n behoorlike studie van die konteks en taal gemaak het nie, sal prediking ook nie los van die wêreld waarbinne dit geskied kan funksioneer nie (Harris 2008:90; Johnston 2001:10; Tubbs Tisdale 2008:75-76). 
Wat daarom binne elke konteks aan die prediking gevra moet word, is die vraag: 'Word die boodskap net gepreek, of ook gehoor?' (vgl. Fry Brown 2008:102; Johnston 2001:9). 'n Vertaling van die homiletiek na die taal van visuele prediking verpak binne die verskeidenheid van visuele sigtelike metafore, kan preke vir vandag se hoorder en/of kyker met nuwe lewe vul en vir mense 'n nuwe waardering daarvoor laat ontwikkel (Hogan 2008:147).

Prediking is en bly steeds die medium - nié die boodskap nie (Hogan 2008:147; Sweet 1999:31). Prediking is bloot die houer wat die water dra (vgl. Hogan 2008:147; Sweet 1999:72); die water is daardie lewende water waarvan Jesus Christus gepraat het (Joh 4:14), naamlik die evangelie van goeie nuus wat lewe bring en die geestelike dors les van elkeen wat daarvan drink.

\section{Literatuurverwysings}

Atkinson, G., 2006, Multi-sensory worship viewed n.d., from http://www. multisensoryworship.com

Barnard, A.C., 1995, Liggaamshouding, liggaamsbeweging en liturgiese dans, Agenda vir die dertiende sinode van Noord-Transvaal (NG Kerk), bl. 218-232.

Barnard, P.H., 2009, 'Relevante prediking in 'n veranderende wêreld van relatiwiteit: 'n ondersoek na deelname aan die erediens en die houding teenoor kerk en prediking onder gelowiges in die konteks van die Paarl', PhD-proefskrif, Departement Praktiese Teologie, Universiteit van Pretoria.

Beach, N., 2004, An hour on Sunday, Zondervan, Grand Rapids, MI.

Blackwood, R., 2009a, Multisensory preaching and teaching, viewed n.d., from http:// www.koinoniablog.net.2009/02/multisensory-preaching-1.html

Blackwood, R., 2009b, Multisensory preaching and teaching. Simply entertainment?, viewed n.d., from http://www.facebook.com/note.php?note_id=82348300952

Brink, V., 1997, Adolossensie in die laaste dekade van die twintigste eeu. Ongepubliseerde werk.

Buitendag, J., 2009, 'Triniteit en triangulasie. Op soek na 'n kosmiese liturgie' in F.G. Immink \& C.J.A. Vos (reds.), God in 'n kantelende wêreld, bl. 220-230, Protea Boekhuis, Pretoria.

Burke, S., 2005, 'Story', in G. Russinger \& A. Field (eds.), Practitioners, voices within the emerging church, pp. 75-76, Regal Books, California.

Campbell, A.V., 1981, Rediscovering pastoral care, Darton, Longman and Todd Ltd, London.

Carstens, C., 1997, Jeugspiritualiteit, Ongepubliseerde werk.

Carter Florence, A., 2008, 'The preaching imagination', in T.G. Long \& L. Tubbs Tisdale (reds.), Teaching preaching as a Christian practice, pp. 116-133, Westminster John Knox Press, London, UK.

Collison, M., 2000, Seven trends to watch in the next decade, viewed n.d., from http:// www.youthspecialties.com/articles/topics/culture/changing.php

Comby, J., 1985, How to read Church History, SCM Press Ltd, London, UK.

De Gruchy, J.W., 2009, John Calvin - Christian Humanist, Evangelical Reformer, Lux Verbi.BM, Wellington, SA

Denison, C., 2006, The artist's way of preaching, John Knox Press, Louisville, KY.

Detweiler, C., 2005a, 'Art is dangerous', in G. Russinger \& A. Field (eds.), Practitioners, voices within the emerging church, pp. 82-83, Regal Books, California.

Detweiler, C., 2005b, 'Christ and Culture', in G. Russinger \& A. Field (eds.), Practitioners, voices within the emerging church, pp. 102-115, Regal Books, California.

Dingemans, G.D.J., 1996, 'Preken in een poste postmoderne konteks', in M. Nel (red.), Prediking - Kommunikasie in konteks, bl. 117-134, Makro Boeke, Voortrekkerhoogte.

Fry Brown, T., 2008, 'The use of language', in T.G. Long \& L. Tubbs Tisdale (eds.), Teaching preaching as a Christian practice, pp. 101-115, Westminster John Knox Press, London, UK.

Garrety, T., 2005a, 'The visual language', in G. Russinger \& A. Field (eds.), Practitioners, voices within the emerging church, pp. 90-91, Regal Books, California.

Garrety, T., 2005b, 'Christ and Culture', in G. Russinger \& A. Field (eds.), Practitioners, voices within the emerging church, pp. 102-115, Regal Books, California.

Harris, J.H., 2008, 'Interpreting the larger Social Context', in T.G. Long \& L. Tubbs Tisdale (eds.), Teaching preaching as a Christian practice, pp. 90-100, Westminster John Knox Press, London, UK.

Henry, M.K., 2000, Multisensory teaching, viewed n.d., from http://www.interdys. org/servlet/compose?section id=5

Hestorff, S., 2005, Youth Ministry Changing, viewed n.d., from http://www. biblicalrecorder.org/content/news
Hogan, L., 2008, 'Creation of form', in T.G. Long \& L. Tubbs Tisdale (eds.), Teaching preaching as a Christian practice, pp. 134-148, Westminster John Knox Press, preaching as
London, UK.

Immink, F.G., 2009, 'God in 'n kantelende wêreld', in F.G. Immink \& C.J.A Vos (eds.), God in 'n kantelende wêreld, bl. 9-17, Protea Boekhuis, Pretoria.

Jensen, R.A., 2005, Envisioning the Word - The use of visual images in preaching, Augsburg Fortress, Minneapolis, MN.

Johnston, G.M., 2001, Preaching to a Postmodern World, Baker Books, Grand Rapids, $\mathrm{MI}$.

Jones, A., 2001, 'Alternative worship', Cutting Edge, Winter, 19-23.

Kimball, D., 2003, Do we need youth ministry anymore?, viewed n.d., from http:// www.youthspecialties.com/articles/topics/culture/need_youth_ministry.php

Lischer, R., 2005, The End of Words, Eerdmans Publishing Company, Grand Rapids, MI. Long, T.G., 2001, Beyond the worship wars, The Alban Institute Inc., Herndon, VA.

Mathewson, S., 2007, The Use of PowerPoint in Preaching, viewed n.d., from http:// blog.preachingtoday.com/2007/05/the_use_of_power_point_in_prea.html

McCrindle, M., 2009, Who is Generation Z?, viewed n.d., from http://s60761. gridserver.com/2009/03/who-is-generation-z/

McDougall, J., 2009, Teaching the visual generation: teachers' responses to art, media and the visual literacy challenge, viewed n.d., from http://www.aare.edu. au/02pap/mcd02235.htm

McLuhan, M. \& Laphan, L.H., 1994, Understanding Media: The Extension of Man, MIT Press, Cambridge, MA.

Miller, C., 1994, The Empowered Communicator, Broadman and Holman, Nashville, TN.

Miller, C., 2006, 'Making the listenable sermon, seeable', in 16th Annual national conference on preaching, Fellowship Church, Dallas, Texas, April 24-26, 2006, CDROM.

Nel, M. (ed.), 1996, Prediking - Kommunikasie in konteks, Makro Boeke, Voortekkerhoogte.

Niemandt, N., 2007, Nuwe drome vir nuwe werklikhede, Lux Verbi.BM, Wellington.

Pagitt, D., 2005, 'Story and evangelism', in G. Russinger G. \& A. Field (eds.), Practitioners, voices within the emerging church, pp. 87, Regal Books, California.

Pagitt, D., 2006, CD-ROM. 'Re-Imagining Preaching', in 16th Annual national conference on preaching, Fellowship Church, Dallas, Texas, April 24-26, 2006, CDROM.

Prokes, M.T., 1996, Toward a theology of the body, Eerdmans Publishing Company, Grand Rapids, MI.

Robinson, H.W., 2006, CD-ROM. Case Study of Creative Exposition, 16th Annual national conference on preaching - April 24-26, 2006, Fellowship Church, Dallas, Texas.

Rognlien, B., 2005, Experiential Worship. Encountering God with heart, soul, mind and strength, Navpress Publishing Group, Colorado Springs, CO.

Romanowski, W.D., 2007, Eyes Wide Open, Brazos Press, Grand Rapids, MI.

Smith, S., 2006, 'Message in the medium of visual illustration', in 16th Annual national conference on preaching, Fellowship Church, Dallas, Texas, April 24-26, 2006, CDROM.

Stevenson, K., 1981, Family Services, SPCK.

Sweet, L.I., 1999, Soul Tsunami, Zondervan, Grand Rapids, MI.

Sweet, L.I., 2006, in 'n onderhoud met Lawrence, R. Second Century Youth Ministry van http://www.LeonardSweet.com/includes/showsweetendArticles.asp?article

Toplak, C., 2004, Teaching political science to visual generations, viewed n.d., from http://www.epsnet.org/2004/pps/Toplak.pdf

Troeger, T.H., 2007, 'Preaching as a language of hope', in C.J.A. Vos, LL. Hogan \& J.H. Cilliers, (eds.), Seeing visions and dreaming dreams: the imaginative power of preaching hope, pp. 59-72, Protea Book House, Pretoria.

Tubbs Tisdale, L., 2008, 'Exegeting the Congregation', in T.G. Long\& L. Tubbs Tisdale (eds.), Teaching preaching as a Christian practice, pp. 75-89, Westminster John (eds.), Teaching preaching
Knox Press, London, UK.

Van Tonder, B.J., 2001, 'Kerkmusiek vir hedendaagse tieners', Mdiac-proefskrif, Departement Praktiese Teologie, Universiteit van SA.

Van Tonder, B.J., 2006, 'Prediking binne die konteks van die hedendaagse gesinserediens', M.A. Teologie, Department Praktiese Teologie, Universiteit van Pretoria.

Vos, C.J.A. \& Pieterse, H.J.C., 1997, Hoe lieflik is u woning, RGN Uitgewery, Pretoria.

Vos, C.J.A., 2007, 'Preaching as a language of hope', in C. J.A. Vos, L.L. Hogan \& J.H. Cilliers, (eds), Preaching as a language of hope, pp. 11-28, Protea Book House, Pretoria.

Warren, T., 2006, 'Investing time for creativity: A long-term plan', 16th Annual national conference on preaching, April 24-26, 2006, Fellowship Church, Dallas, Texas, CD-ROM

Willingham, T., 2007, Media in worship, viewed n.d., from http://www.umcmcd.org/ manual/media-tw.html

Woodbridge, B.A., 2007, Preaching as subversive activity, viewed n.d., from http:// www.religion-online.org/showarticle.asp?title $=1616$

Young, E., 2006, CD-ROM, 'Preaching creatively', 16th Annual national conference on preaching, Fellowship Church, Dallas, Texas, April 24-26, 2006.

Zander, D., 2006, 'Creative preaching in postmodern culture', 16th Annual national conference on preaching, Fellowship Church, Dallas, Texas, April 24-26, 2006, CDROM. 